\title{
AFFILIATED SOCIETIES NEWS
}

\section{SUTTON \& DISTRICT MEDICAL SOCIETY}

FRIDAY, DeCEMBER 6th.

Speaker: Dr. F. Hernaman Johnson, D.M.R.E.

"The Pharmacology and Therapeutics of Radiation."

FRIDAY, JANUARY IOth.

Speaker: Dr. Alexander Joe, M.R.C.P.

"Recent Methods in the Prevention and Treatment of the Common Infectious Diseases."

FrIDAY, JANUARY 24th.

Clinical Meeting at Sutton Hospital.

FrIDAY, February 7 th.

Speaker: P. Jenner Verrall, F.R.C.S. "Common Fractures."

FridAY, MARCH 6th.

Speaker: Dr. Donald Paterson, F.R.C.P.

"Common acute diseases of Infancy and early Childhood."

FrIDAY, APRIL 3rd.

Speaker:

Friday, May Ist. ANNUAL DinNeR, 7.45.

The Visiting Speakers will be the guests of the Society.

Meetings are held at The Greyhound Hotel, Carshalton, at 8.45 sharp. "Greyhound" 'Phone: Wallington I5II,

Hon. Sec.: T. H. Whittington, Oakfield, Carshalton Road, Sutton.

\section{THE ST. JOHN'S HOSPITAL DERMATOLOGICAL SOCIETY (INCORPORATING} THE LONDON DERMATOLOGICAL SOCIETY.)

Meetings of The St. John's Hospital Dermatological Society (incorporating The London Dermatological Society) will be held at St. John's Hospital, 49, Leicester Square, at 4.I5 p.m. on:-

Wednesday, January 22nd-Clinical Cases.

February 26th-Clinical Cases and Paper.

", March 25th-Clinical Cases.

", April 22nd-Clinical Cases and Paper.

", May 27th-Clinical Cases and Annual General Meeting.

, June 24th-The Prosser White Annual Oration.

A Meeting of the Society was held at St. John's Hospital on Wednesday, October 23rd, at 4.I5 p.m. Dr. J. E. M. Wigley, President, in the Chair.

Clinical Cases were shown as follows:-

Case 1.-Dr. Wigley showed a case of a girl aged 7 years who had a lesion on her left leg for six months, which he thought was a Linear Nævus. He thought that the case was of interest, for although it was most like a linear nævus, other diag- noses had been suggested such as atypical psoriasis with lichenification. A section had been taken by $\mathrm{Dr}$. Muende, who reported as follows: "The section showed marked acanthosis, which did not resemble that found in psoriasis. The parakeratosis, 
unlike that in psoriasis, alternated with hyperkeratosis. The corium showed masses of numerous cells, a few of which were of an inflammatory nature, and some of which suggested that they were of nævoid origin. He thought the section supported the diagnosis of a linear nævus."

The demonstrator asked the meeting for advice with regard to, treatment. The patient had been treated for psoriasis with the usual external applications and also $\mathrm{X}$-rays for three months, but without improvement.

Dr. MacLeod said that he was inclined to regard the condition as a linear nævus. The only other condition that it resembled was linear lichen planus. The lesion was much masked by treatment, which accounted for the redness. It was not uncommon for nævoid conditions to make their appearance late in life.

Dr. Griffith agreed with the diagnosis, which he said would have been more obvious if the irritant application had not been employed.

Dr. Brain said he had a similar case where the lesion ran up the inside of the thigh, and which he regarded as a linear nævus. He had seen others which began early in life with lesions on the foot which later extended up the leg. The scaliness in this case was certainly suggestive of psoriasis.

Dr. Wigley said that the patient had been without treatment for three weeks and that he would welcome any suggestions as to treatment. Was there any other method of treatment other than excision?

Dr. Brain said he had used radium and $\mathrm{CO}_{2}$ in this type of case, but the results were very disappointing.

Case 2.-Dr. Sibley showed a single woman, aged 29, who, for the last 8 months, had extensive ulcerations on the left arm which were very inflamed, had a fotid discharge, and were very painful. This case, which had been shown in May last (Transactions, 1935, p.67), had since been treated in the in-patient department by Dr. MacLeod with an excellent result.
The demonstrator recalled that the diagnosis then was artefact, the ulcerations being attributed to the use of kleenoff, which was a very caustic alkali. There was a question of the patient having tuberculosis, but examination at the time did not reveal the presence of pulmonary tuberculosis. There was no definite anæsthesia of the palate or conjunctivæ, nor was she able to tolerate pin pricks on her left forearm.

Dr. MacLeod said that he treated her with boric starch poultices, and later with simple drying lotions. He was astonished at the rapidity with which the lesions healed, and the comparative freedom from keloid formation.

Dr. Griffith said he saw the patient on several occasions during Dr. MacLeod's absence, and covered the affected parts with elastoplast. $\mathrm{He}$, too, was pleasantly surprised with the final result.

Dr. Wigley said it would be interesting to follow these cases up with a view to determining if they are subject to recurrence, or suffer from any more apparent mental disturbance.

Case 3.-Dr. Sibley's patient, a woman aged 51, who had, on and off for 18 months, a small tumour about $\frac{1}{6}$ th of an inch in diameter on the outside of her tongue. This disappeared completely at times, but the patient thought the duration of the present tumour made it likely that it was going to remain solid.

Dr. Burford asked if the surrounding teeth were sharp, as he thought that this factor could have been the cause of the condition.

Dr. Muende said that he thought the most likely diagnosis to fit in with the history was that of a fibromyxoma, for when undergoing myxomatous change these tumours might disappear completely, but finally, with the overgrowth of fibrous tissue, could develop into a solid tumour such as the one presented in this case. He thought, therefore, that simple excision would give a satisfactory result, as these tumours were not liable to undergo malignant change. 
Case 4.-Dr. Sibley showed a young man, aged 22, with what he considered to be a variety of Acne Varioliformis. The condition, which was of 2 years' duration, was of an inflammatory nature, which left scarring at the back of the neck. Although acne varioliformis rarely attacks people at this age, the scarring was, in his opinion, highly suggestive of the condition.

Dr. MacLeod said that he thought they were sycosiform lesions leading to scarring, rather than true acne varioliformis.

Dr. Griffith suggested the diagnosis of dermatitis papillaris capillitii, or sycosis nuchæ.

Dr. Wigley said he thought they were suggestive of acne keloid.

Dr. MacLeod could not agree with the diagnosis of acne keloid as the lesions were not big enough, and the folliculitis too active for this condition.

Dr. Michæl agreed with Dr. MacLeod that it was a pustular folliculitis of a low grade. He used toxoid in such cases, but so far without good result.

Dr. Brain reported that he had been fortunate in obtaining satisfactory cure in a few cases with anti-virus.

Case 5.-Dr. Brain's case was a married man, aged 26, who had a healthy child of 1 year. The patient had an ulcerated lesion on his nose of 12 months' duration, and smaller punched out lesions on his hands for 6 months. The lesion on his nose resembled lupus tumidus, but its growth was too rapid for this condition. The Wasserman reaction was strongly positive. In view of the fact that he denied infection, and taking into account his youth, Dr. Brain asked whether one could consider this a case of congenital syphilis, even in the absence of Hutchinson's triad.

Dr. Wigley said that it was an unusual case, as one very rarely saw such mutilating lesions of syphilis nowadays.

Dr. Muende asked if the senior physicians found that gummata were more destructive in younger men than in those of 40 years and upwards. He had had a similar case of a man aged 24, who, within 9 months had the orbit of his face and mouth destroyed by a gummatous lesion, in the absence of any suitable antisyphilitic treatment.

Dr. Katzenellenbogen said that he was of the opinion that it was a case of acquired and not congenital syphilis, and the fact that the ulnar side of the patient's left hand was affected more than other parts, can be attributed to trauma acquired during his occupation as an upholsterer. Destructive gummata in young people were quite common in Palestine. In certain isolated villages in Palestine, such as the Hebron area, Nahalin, Beisan, etc., where syphilis is endemic, it is quite common to find such acquired infection in children of 2 and 3 years of age. Infection in children and adults is probably often acquired by abrasions of the buccal mucosa through drinking from vessels with long and frequently sharp spouts. Syphilis of the buccal mucosa and peri-oral region is, therefore, a common feature among these people. Gummata are formed not only in the areas involved by the usual traumata but also, among the poor Arab population of these villages, in the sites of scratching following infestation with pediculi, such as the buttocks and the scapular regions. Secondary coccal infection usually gives rise to the more destructive gummata lesions. Owing to the difficulty of treating such cases at suitable clinics, the following method, at the suggestion of the speaker, was adopted by the Government in 1928. At Nahilin the sanitary inspectors visit these patients, who, in their presence, are made to take $\frac{1}{4} \mathrm{gr}$. tablets of spirocid; two tablets on the first day; three tablets on the second and third days; miss three days, then repeat, until 56 tablets have been taken. The results have been highly satisfactory, and although spirocid cannot be claimed to be the ideal treatment in individual cases, it is to be recommended in endemic areas with a view to controlling the spread from infective cases.

Dr. Alamud-Din said that the Government were now actively engaged in an antivenereal campaign in three main centres, in Jerusalem, Haifa, and Jaffa. 